Sharif University of Technology
Scientia Iranica
SCIENTIA
I RAN I C A
http://scientiairanica.sharif.edu

\title{
Application of endurance time method in seismic analysis of bridges
}

\author{
E. Ghaffari*, H.E. Estekanchi, and A. Vafai \\ Department of Civil Engineering, Sharif University of Technology, Tehran, P.O. Box 11155-9313, Iran.
}

Received 21 November 2017; received in revised form 1 July 2018; accepted 27 October 2018

\author{
KEYWORDS \\ Endurance time \\ method; \\ Bridge; \\ Nonlinear dynamic \\ analysis; \\ Incremental Dynamic \\ Analysis (IDA); \\ Intensifying dynamic \\ excitation; \\ Life cycle cost \\ analysis.
}

\begin{abstract}
In this paper, the application of Endurance Time (ET) method to the seismic analysis of bridges is elaborated. ET method is a novel seismic analysis method based on time history analysis in which a structure is subjected to a predefined intensifying acceleration function. First, six concrete bridges were modeled in this study. Three Endurance Time Acceleration Functions (ETAFs) were applied to the models, and the average of responses was calculated. Next, the time history analysis was conducted using seven real accelerograms that are scaled using the method recommended by Federal Highway Administration (FHWA) to be compatible with the design spectrum of American Association of State Highway and Transportation Officials (AASHTO) guideline for a site with soil type $\mathrm{C}$ in Berkeley, California. The average of the responses of these analyses is considered as a reference. By scaling the mentioned accelerograms over a wide range of hazard levels, Incremental Dynamic Analysis (IDA) is performed. Finally, the comparison of the response of ET analysis and time history analysis and also the comparison of Endurance Time Analysis (ETA) and IDA curves revealed good agreement. The major advantage of ET method over time history and IDA methods is the need for less computational effort for performing the analysis. Such time efficiency was achieved due to the possibility of predicting responses by a smaller number of analyses despite maintaining the necessary accuracy.
\end{abstract}

(C) 2020 Sharif University of Technology. All rights reserved.

\section{Introduction}

Damage and collapse of bridges around the world due to recent earthquakes has led engineers to pay greater attention to the seismic vulnerability of bridges as critical structures in transportation networks [1,2]. The first step in the design or seismic retrofit of bridges is to

\footnotetext{
*. Corresponding author. Tel.: +982166164296;

Fax: +982166014828

E-mail addresses: ghaffari@alum.sharif.edu (E. Ghaffari); stkanchi@sharif.edu (H.E. Estekanchi); vafai@sharif.edu (A. Vafai)
}

doi: $10.24200 /$ sci. 2018.5041 .1382 know their expected performance during earthquakes. An unrealistic prediction of bridge behavior during an earthquake leads to improper design, resulting in an incorrect response that can, in turn, lead to unforeseen damage or even collapse of the bridge. The root of this problem is sometimes originated from the excessive simplification of the modeling and analysis of a bridge during its seismic design or retrofit [3].

To investigate the seismic behavior of a structure, two important issues should be noted: first, creating a model that includes vital details while maintaining its simplicity and, second, selecting a suitable method for the analysis of the model by considering the accuracy and saving analysis time [4]. It is generally recognized 
that it is uneconomical to design a bridge to resist a severe earthquake elastically [5]. Excessive use of accurate analysis methods imposes an enormous burden of calculations on the designer, while simpler methods are also capable of predicting the seismic behavior of a structure with acceptable accuracy [6]. The application of Endurance Time (ET) method as a time history-based method has been quite successful in the seismic analysis of structures in both linear and nonlinear ranges in building frames and some other structures [7,8]. ET analysis enjoys high accuracy in predicting the behavior of structures despite the shortened total analysis time [9]. In this paper, the advantages of ET analysis over time history method and Incremental Dynamic Analysis (IDA) are demonstrated in the seismic analysis of bridges.

\section{Analysis}

\subsection{Endurance Time (ET) method}

Estekanchi et al. [10] proposed the idea of ET method. The concept of ET can be explained considering a hypothetical experiment. According to Figure 1, a dynamic excitation is applied to three different structures with unknown structural properties built on a shaking table by a predetermined acceleration function. The amplitude of oscillation increases gradually. As time elapses, it is assumed that the frame A collapses after $8 \mathrm{~s}$, frame $\mathrm{C}$ collapses after $13 \mathrm{~s}$, and the frame B collapses after $18 \mathrm{~s}$. Thus, according to the definition, the ET of the frames A, C, and B for a specific failure criterion which is a complete collapse in this case is $8 \mathrm{~s}, 13 \mathrm{~s}$, and $18 \mathrm{~s}$, respectively. If the three frames are designed with three different methods for a unique purpose, it can be found that frame B has the largest ET and the best performance from the endurance perspective. Hence, ET method is a dynamic analysis method that aims to predict the seismic response of a structure by applying a predefined intensifying dynamic loading [11].

\subsection{The characteristics of acceleration functions in ET method}

For the purpose of this study, it is assumed that ET acceleration functions are calibrated so that their response spectrum until reaching a target time can be in agreement with the template spectrum, which is a code design spectrum or the average spectrum of a set of selected ground motions $[12,13]$. The characteristic of the acceleration functions is the linear increase of its amplitude with time. To achieve this objective, a linear ratio should exist between the response spectrum at a specific time interval and that at the target time (e.g., 10th s), which approximately equals the template spectrum. For instance, the response spectrum of the acceleration function until the 5 th and 15 th s should be half and 1.5 times larger than the template spectrum, respectively. The characteristics of the Endurance Time Acceleration Functions (ETAFs) are presented in Figure 2.

\subsection{The endurance time acceleration functions used in this study}

Ever since the formation of ET method, several acceleration functions have been created with different objectives. Each set of acceleration functions is optimized in the generation step to be compatible with the
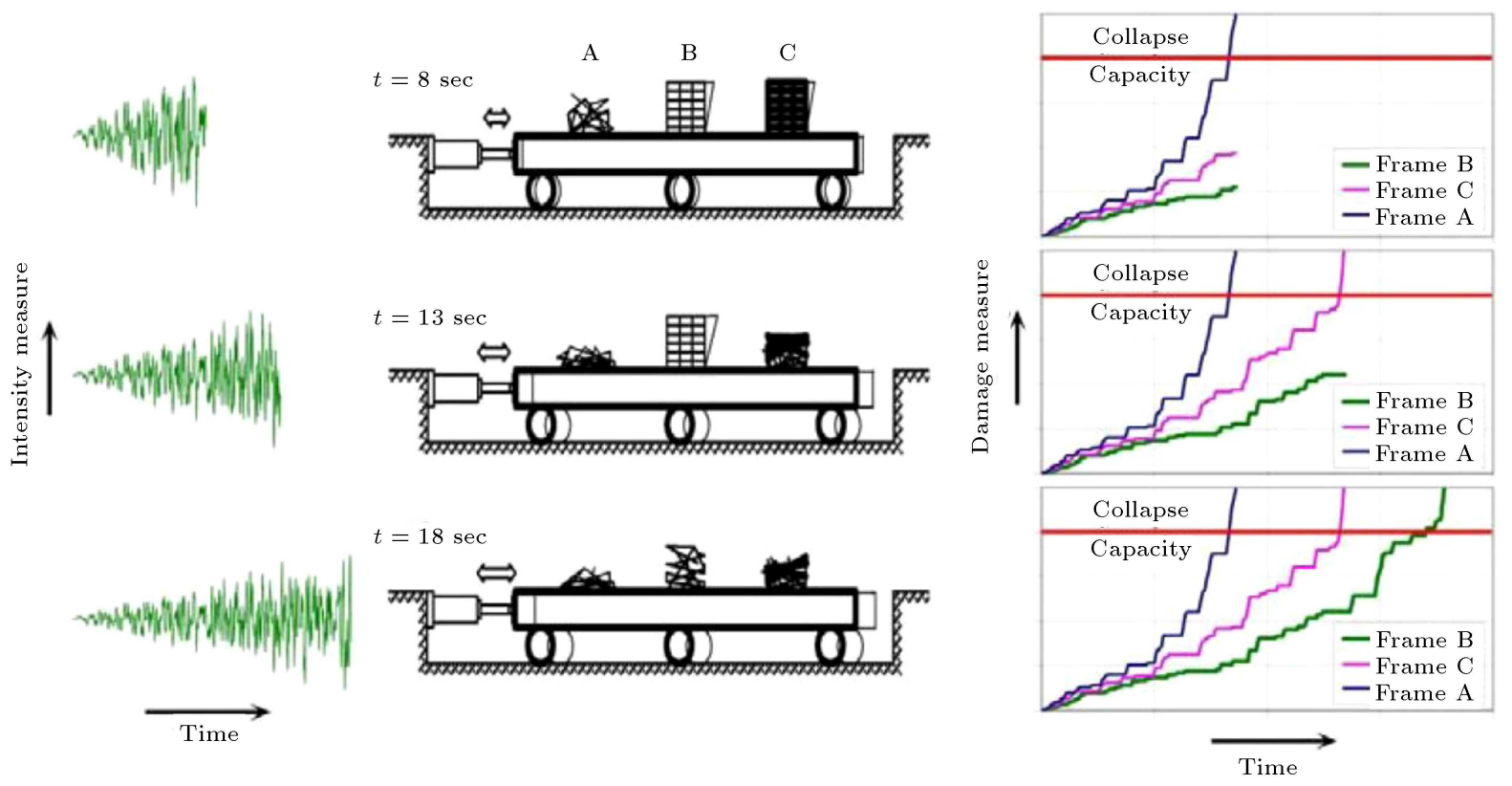

Figure 1. The shaking table hypothetical experiment for explaining the concept of Endurance Time (ET) method [7]. 


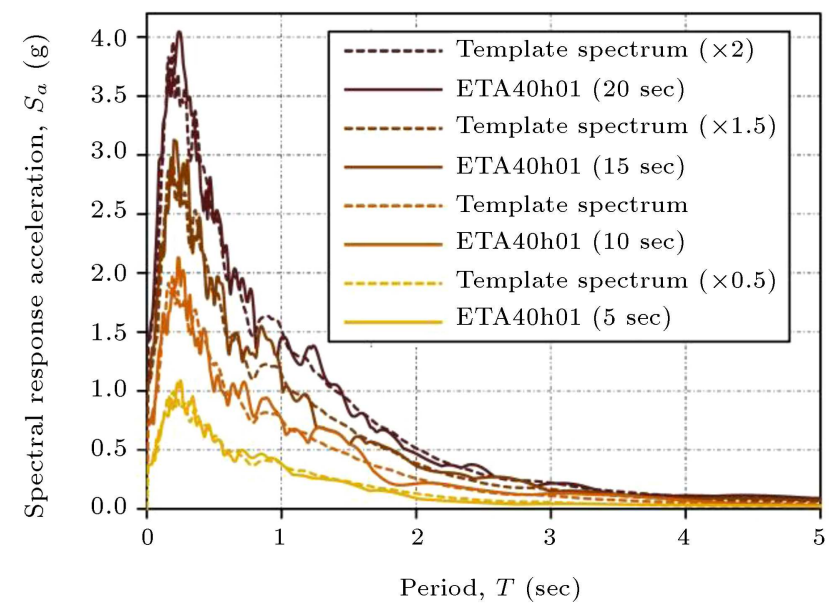

Figure 2. Acceleration response spectra at different time intervals of excitation for ETA40h01 (as an example).

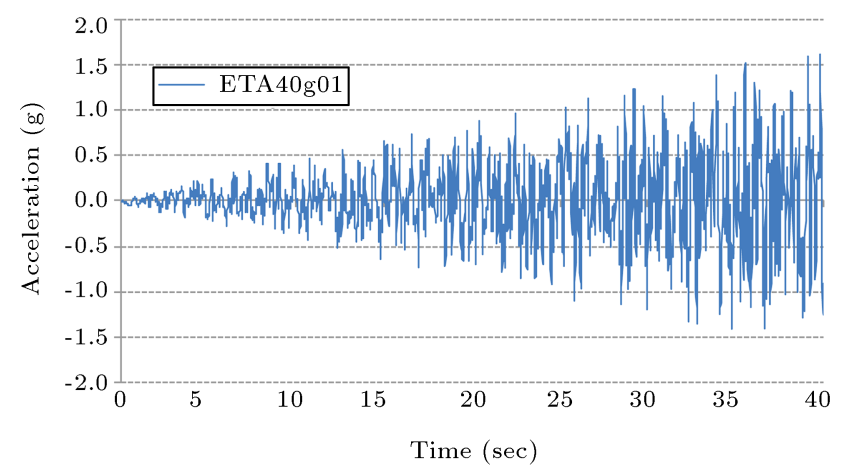

Figure 3. A typical Endurance Time (ET) acceleration function (ETA40g01).

template spectrum [14]. In the initial studies, the acceleration functions of ET method were optimized based on Iranian National Building Code (INBC) 2800 [15] spectrum. In this paper, acceleration functions series ETA40g are employed, which are optimized based on ASCE7-05 [16] design spectrum as the template spectrum. One of the ET acceleration functions used in the analysis of bridges in this study is shown in Figure 3 [14].

One of the characteristics of the ET acceleration functions is that the response spectrum produced by a window from $t=0$ to $t=t_{1}$ is consistent with a spectrum as a function of $t_{1}$. The acceleration functions, "ETA40g" series, are designed so that their response spectrum at the 10th s can be consistent with ASCE7-05 design spectrum characterized by parameters $S_{S}=1.5, S_{1}=0.6, F_{a}=1.0, F_{V}=1.3$, and $T_{L}=8 \mathrm{~s}$.
To carry out ET analysis, the first step is scaling the acceleration functions for each model so that their average spectrum can be consistent with the site design spectrum, which is the design spectrum of FHWA 2006 [17], for a site in Berkeley in California with the soil type C. This spectrum corresponds to an event of 1033-year (say 1000) return period (7\% probability of exceedance in 75 years). The coefficient associated with the generation of this spectrum is presented in Table 1.

Since the site spectrum and ASCE7-05 spectrum, which is the base template spectrum of "ETA40 g" in the generation day, are not different in shape except in scale, it suffices to keep the two mentioned spectrums consistent and obtain the same scale factor for analyzing all models. Through the aforementioned method, a scaling factor of 2.20 makes ET spectrum in the target time (i.e., 10th s.) compatible with the site.

Since ETA40 g series are one-directional acceleration functions in 3D analysis, a scale factor of 2.20 for two horizontal directions and a factor of $0.67 \times 2.20$ for the vertical direction are used. To eliminate the dispersion that results from the random selection of the points in the ET acceleration function generation, the proposed method is applied in three steps. As a result, ETAg123, ETAg231, and ETAg312 constitute the tri-directional acceleration functions. For instance, ETAg123 suggests the use of scaled ETA40g01 in the main direction, use of scaled ETA40g02 in a direction perpendicular to the main direction, and finally the use of ETA $40 \mathrm{~g} 03$ with a scale factor of $0.67 \times 2.20$ in the vertical direction.

To illustrate the results of ET analysis, the response histories corresponding to ETAg123, ETAg231, and ETAg312 are extracted, and their maximum response curves are drawn. At specific time $t_{1}$, these curves exhibit the maximum absolute value of responses at a time interval of 0.0 to $t_{1}$. To increase the resolution of the obtained response, the average of all three maximum response curves is used. Finally, this curve is smoothed using a moving average method to obtain ET curve of the bridge.

\section{The employed models}

In this study, six bridge models whose geometric properties are presented in Table 2 are employed. These models include actual structures and in-service ones, which are based on Aviram et al. [18]. The finite element model of a typical bridge in this study (i.e., LADWP bridge) is presented in Figure 4.

Table 1. The coefficients of generating response spectrum of 1033-year design based on the Federal Highway Administration (FHWA) 2006, damping ratio of $5 \%$.

\begin{tabular}{ccccccccccc}
\hline Parameters & Zip code & Site & $\boldsymbol{S}_{\boldsymbol{1}}$ & $\boldsymbol{S}_{\boldsymbol{s}}$ & $\boldsymbol{F}_{\boldsymbol{v}}$ & $\boldsymbol{F}_{\boldsymbol{a}}$ & $\boldsymbol{S}_{\boldsymbol{D} \boldsymbol{S}}$ & $\boldsymbol{S}_{\boldsymbol{D} \mathbf{1}}$ & $\boldsymbol{T}_{\mathbf{0}}$ & $\boldsymbol{T}_{\boldsymbol{s}}$ \\
\hline Value & 94704 & $\mathrm{C}$ & 0.87 & 2.29 & 1.3 & 1 & 2.29 & 1.13 & 0.10 & 0.49 \\
\hline
\end{tabular}


Table 2. Summary of bridge properties used in the analysis [18].

\begin{tabular}{|c|c|c|c|c|c|c|c|c|c|}
\hline Bridge & $\begin{array}{l}\text { Pier } \\
\text { type }\end{array}$ & $\begin{array}{c}\text { No. } \\
\text { spans }\end{array}$ & $\begin{array}{l}\text { Length } \\
(\mathrm{m})\end{array}$ & $\begin{array}{c}\text { Width } \\
(\mathbf{m})\end{array}$ & $\begin{array}{l}\text { No. } \\
\text { cols. }\end{array}$ & $\begin{array}{c}\text { Col. } \\
\text { diam. } \\
(\mathrm{m})\end{array}$ & $\begin{array}{c}\text { Col. } \\
\text { height } \\
\text { (m) }\end{array}$ & $\begin{array}{c}\text { Super. } \\
\text { depth } \\
(\mathbf{m})\end{array}$ & $\begin{array}{c}\text { Cap } \\
\text { beam } \\
\text { dim. } \\
(m)\end{array}$ \\
\hline Adobe & Multi-col. & 2 & $61.9(31.4+30.5)$ & 12.50 & 2 & 1.22 & 8.11 & 1.25 & $2.13 \times 1.25$ \\
\hline Route 14 & Multi-col. & 2 & $87.2(44.2+43.0)$ & 16.37 & 2 & 1.65 & 11.55 & 1.75 & $2.30 \times 1.75$ \\
\hline LaVeta & Multi-col. & 2 & $91.1(47.2+44.2)$ & 23.01 & 2 & 1.70 & 7.74 & 1.90 & $2.30 \times 1.90$ \\
\hline LADWP & Multi-col. & 3 & $79.9(23.8+32.3+23.8)$ & 12.68 & 4 & 1.37 & 7.80 & 1.30 & $2.00 \times 1.30$ \\
\hline MGR & Single-col. & 3 & $111.6(33.5 \times 2+44.5)$ & 12.89 & 2 & 1.83 & 11.92 & 1.90 & - \\
\hline W180 & Single-col. & 4 & $205.4(43.6 x 2+59.1 x 2)$ & 12.56 & 3 & 1.83 & 8.05 & 2.36 & - \\
\hline
\end{tabular}

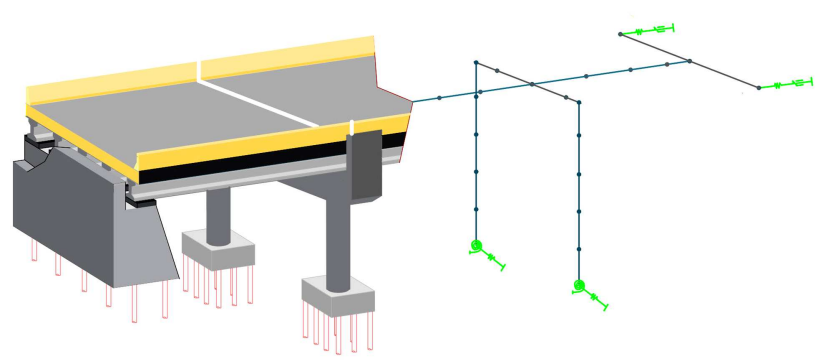

Figure 4. LADWP as one of the defined models.

\section{Time history analysis}

FEMA P695 guideline [19] in Section A.7 provides some insight into the selection of accelerograms. According to these recommendations, seven accelerograms on the type $\mathrm{C}$ soil with a magnitude greater than 6.5 Richter were taken from the PEER database [20]. The properties of these accelerograms are shown in Table 3.

The selected accelerograms were scaled based on the method proposed in FHWA 2006 [17]. The scaling method was used to match the average response spectrum of the accelerograms with the code design response spectrum of the Berkeley in California on the type $\mathrm{C}$ soil. This spectrum is taken from the FHWA 2006 [17] for a 1033-year (say 1000) return period event ( $7 \%$ probability of occurrence in 75 years). The coefficient associated with the generation of this spectrum is presented in Table 1 . The scaling factors for each model-accelerogram pair are presented in Table 4.

Figure 5 shows the design response spectrum in

Table 3. The properties of the accelerograms employed.

\begin{tabular}{|c|c|c|c|c|c|c|c|c|}
\hline $\begin{array}{c}\text { Record } \\
\text { ID }\end{array}$ & Event & Year & $\mathbf{M}$ & $\begin{array}{c}\mathbf{R} \\
(\mathrm{km})\end{array}$ & $\begin{array}{c}\text { PGA-major } \\
(\mathrm{g})\end{array}$ & Station & Soil & Mechanism \\
\hline LOMAP/GH & Loma Prieta & 1989 & 6.9 & 11.0 & 0.282 & Gilroy historic & $\mathrm{C}$ & Reverse-oblique \\
\hline LOMAP/STG & Loma Prieta & 1989 & 6.9 & 13.0 & 0.512 & Saratoga - Aloha Ave & $\mathrm{C}$ & Reverse-oblique \\
\hline IMPVALL/H-PTS & Imperial Valley & 1979 & 6.5 & 14.2 & 0.204 & Parachute Test Site & $\mathrm{C}$ & Strike-slip \\
\hline WHITTIER/A-ALH & Whittier Narrows & 1987 & 6.0 & 13.2 & 0.414 & Alhambra, Fremont Sch & $\mathrm{C}$ & Reverse-oblique \\
\hline NORTHR/CCN & Northridge & 1994 & 6.7 & 25.7 & 0.256 & LA - Century City CC N & $\mathrm{C}$ & Reverse \\
\hline CHICHI/CHY & Chi-Chi, Taiwan & 1999 & 7.6 & 15.3 & 0.277 & CHY029 & $\mathrm{C}$ & Reverse-oblique \\
\hline NORTHR/ORR & Northridge & 1994 & 6.7 & 22.6 & 0.568 & Castaic - Old Ridge Route & $\mathrm{C}$ & Reverse \\
\hline
\end{tabular}

Table 4. Scaling factors for each accelerogram in bridge models.

\begin{tabular}{lccccccc}
\hline \multirow{2}{*}{ Record ID } & \multicolumn{7}{c}{ Bridge models } \\
\cline { 2 - 8 } & $\boldsymbol{T}_{\mathbf{1}}=\mathbf{1 . 0 0} \mathbf{~ s}$ & Adobe & Route 14 & LaVeta & LADWP & MGR & W180 \\
\hline LOMAP/GH & 2.15 & 4.34 & 4.72 & 4.26 & 4.42 & 5.30 & 4.32 \\
LOMAP/STG & 4.40 & 2.39 & 2.60 & 2.35 & 2.43 & 2.92 & 2.38 \\
IMPVALL/H-PTS & 4.33 & 6.00 & 6.53 & 5.89 & 6.11 & 7.33 & 5.98 \\
WHITTIER/A-ALH & 2.38 & 2.96 & 3.22 & 2.90 & 3.01 & 3.61 & 2.95 \\
NORTHR/CCN & 5.98 & 4.78 & 5.20 & 4.69 & 4.87 & 5.84 & 4.76 \\
CHICHI/CHY & 2.95 & 4.42 & 4.81 & 4.34 & 4.50 & 5.40 & 4.40 \\
NORTHR/ORR & 4.77 & 2.15 & 2.34 & 2.11 & 2.19 & 2.63 & 2.15 \\
\hline
\end{tabular}




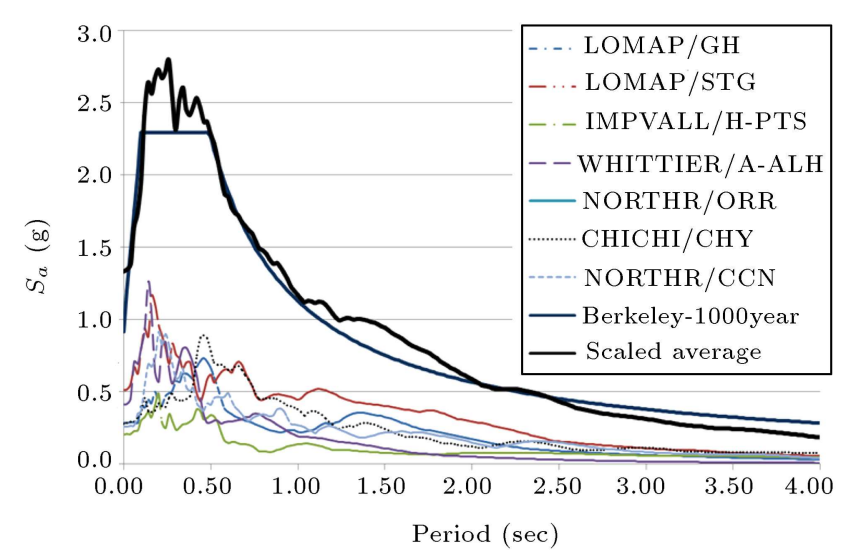

Figure 5. design response spectrum in conjunction with the spectrums of unscaled accelerograms and the average of scaled accelerograms using the method of Federal Highway Administration (FHWA) 2006 for the hypothetical structure with $T=1.00 \mathrm{sec}$. (damping ratio $=5 \%$ ).

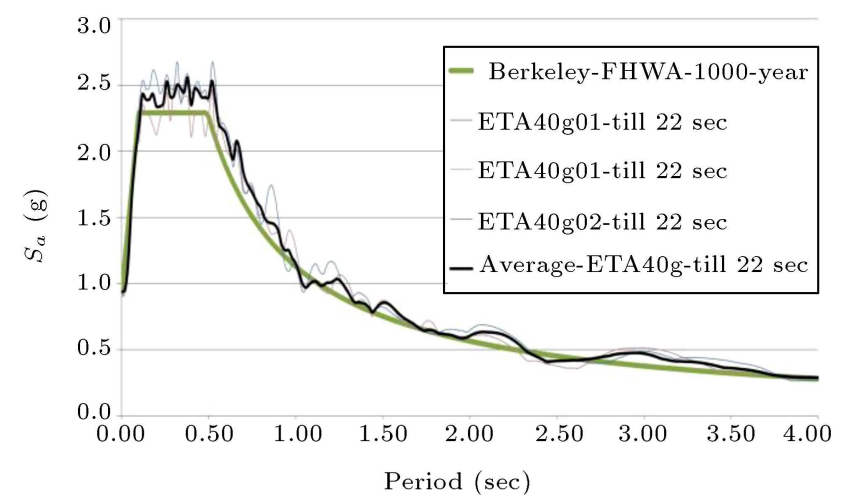

Figure 6. Design response spectrum in conjunction with the spectrums of ETA $40 \mathrm{~g}$ acceleration functions till the 22 nd s (damping ratio $=5 \%$ ).

conjunction with the spectrums of unscaled accelerograms and the average of scaled ones using the method of FHWA 2006 for a hypothetical structure with $T=$ 1.00 sec. The design response spectrum in conjunction with the spectrums of ETA $40 \mathrm{~g}$ acceleration functions until the 22nd sec is presented in Figure 6.

\section{Comparison of ET method and IDA}

IDA method is aimed at analyzing a structure using a suite of accelerograms, each scaled to several Intensity Measure (IM) levels that are designed to have the structure responses from elastic to extremely nonlinear range [21]. Maximum responses for all predefined IM analyses are then calculated and plotted versus an Engineering Demand Parameter (EDP) in a coordinate system [22]. In doing so, the seismic responses of a structure in a wide range of forces are estimated.

ET method is very similar to IDA; for instance, in the former method, a predefined intensifying acceleration function is applied rather than some real accelerograms and that the seismic responses of a modeled structure are evaluated in a wide continuous range of elastic to highly nonlinear in only one continuous analysis.

\subsection{From ET time to other engineering IM parameters}

Since the time duration of analysis in ET method is not a common parameter for expressing the responses of structures, substituting common parameters such as PGA, Spectral acceleration $\left(S_{a}\left(T_{1}\right)\right)$, seismic hazard return period, annual rate of exceedance, and annual probability of exceedance for time in the evaluation and expression of the performance of the structures is highly important $[23,24]$. As a sample, in this study, the seismic responses of the bridges are represented by two different parameters. $S_{a}\left(\mathrm{~T}_{1}\right)$ and seismic hazard return period are used as the substitutions of the time parameter in ET method.

\section{Results and discussion}

\subsection{ET analysis versus time history}

In the process of time history analysis of each bridge, the average of the responses to seven accelerograms is considered as the response of the structure. This response corresponds to the value of ET curve in the target time. As previously noted, the target time for these models is $10.00 \mathrm{sec}$.

The diagrams of Figure 7 , which are plotted for Adobe model, present the parameters of displacement of cap beam's center node, base shear, and rotation of top hinge at one of the columns. In Figure 7, the diagrams of structure responses are plotted for the seven accelerograms of time history method and, also, the three ETAFs. The average of the responses associated with each of these methods is presented as a horizontal line. The level difference between these two horizontal lines indicates the error of ET method. In addition, as can be seen, the dispersion of responses for seven time-history accelerograms is more than that for three ETAFs.

Figure 8 depicts the maximum base shear curves of ETAg123, ETAg231, and ETAg312 analyses beside their average curve and ET curve for the Adobe model. Furthermore, the base shear obtained through the time history method, which is the average of the seven analyses besides the average plus and minus one standard deviation, is plotted. It is observed that, at the target time, there is good agreement between the responses of ET and time history methods.

To obtain the response of the bridges at a specific hazard level, it is only required to determine the time corresponding to that level and read the value of response on the ET curve at that time. This 

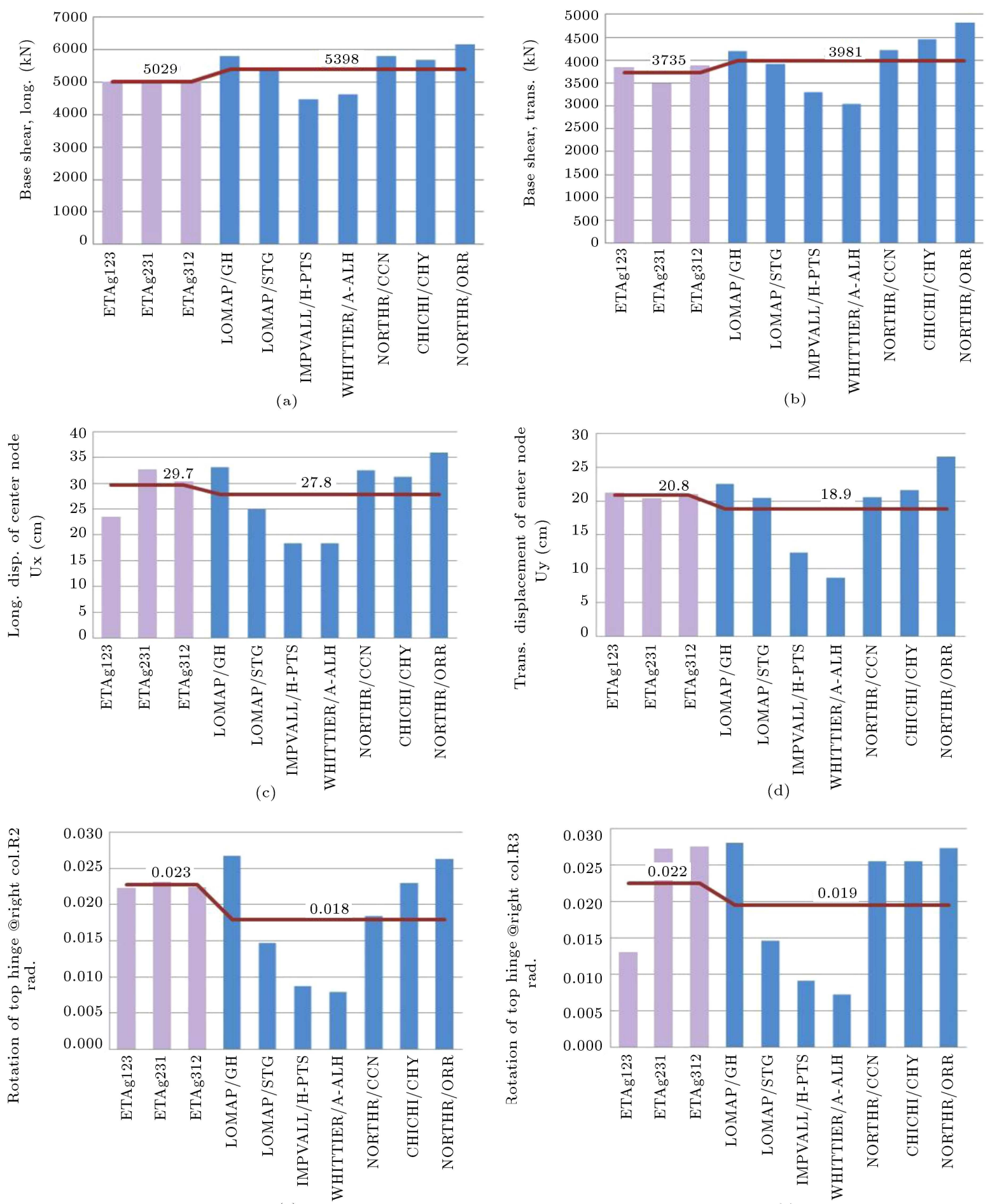

(e)

(f)

Figure 7. Adobe model responses: (a) \& (b) Longitudinal and transverse base shear, (c) \& (d) displacement of capbeam central node in longitudinal and transverse directions, and (e) \& (f) rotation of the top hinge of the right column in directions R2 and R3.

is one of the significant advantages of ET method compared to other seismic analysis methods such as IDA [25].

To exhaustively compare the analysis methods, it is appropriate to plot a diagram that indicates the structure response of a specific parameter in all six models.

Figure 9 illustrates the correlation between ET and time history analyses to predict the longitudinal and transverse base shears of the bridges, the longitudi- 


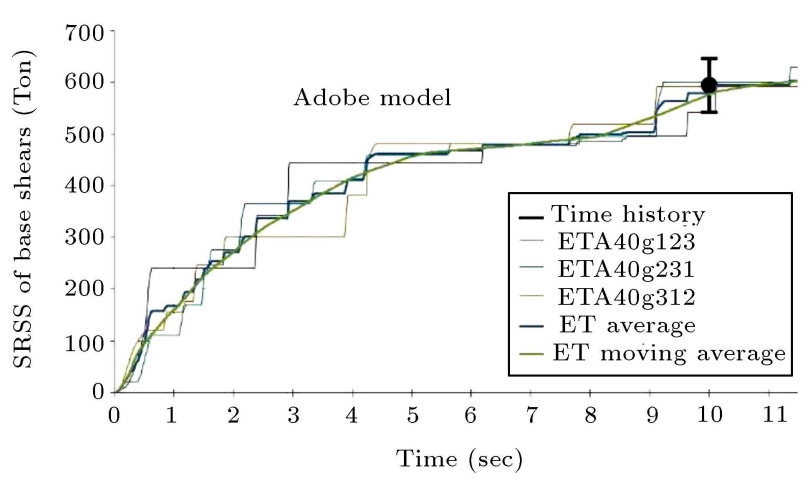

Figure 8. The diagram of Endurance Time (ET) response for ETA40 g series, average and moving average next to the average response, and average plus and minus the standard deviation of the time history of Square Root of the Sum of the Squares (SRSS) of base shear in the Adobe model.

nal and transverse displacements of cap beam's center node, and also the rotation of top hinge of one of the columns. Each of the diagrams is associated with a specific parameter in all models such that each point in these diagrams has an abscissa equal to the structure response obtained by the time history method for that specific parameter. The ordinate of the mentioned point is the value of the intended parameter obtained from ET analysis. After specifying all the points in the diagram for all six models, a line is fitted to them. A dashed line with a slope of $45^{\circ}$ is plotted as a baseline, indicating zero error. The difference between the slope of the fitted line and the baseline is the indicator of the error of ET method for predicting the associated parameter.

\subsection{ET analysis versus IDA}

To compare ET method with IDA, two EDPs for the displacement of a top node in a column and the drift ratio of columns are considered. First, by mapping the time in ET method to $S_{a}\left(T_{1}\right)$, the IDA curves for the seven mentioned real earthquake records, the mean IDA curve, and $16 \%$ and $84 \%$ curves are plotted. On the other hand, the average of three ET response curves and their moving average, called ET curve, are plotted in Figure 10. The figure reveals good agreement between IDA and ETA.

As an alternative, the time parameter in ET method is replaced by the seismic hazard return period. Figure 11 shows the column drift ratio versus the seismic hazard return period (mapped from ET analyzing time) for the LADWP model. Of note, mapping time in ET method to $S_{a}\left(T_{1}\right)$ or to the seismic hazard

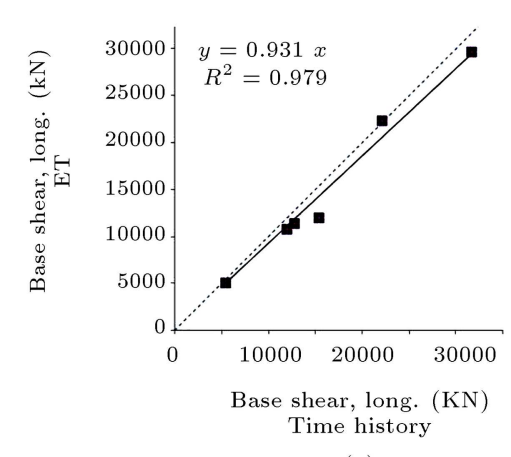

(a)

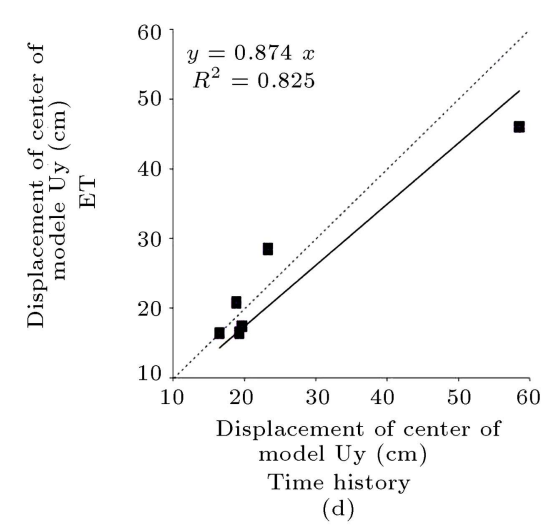

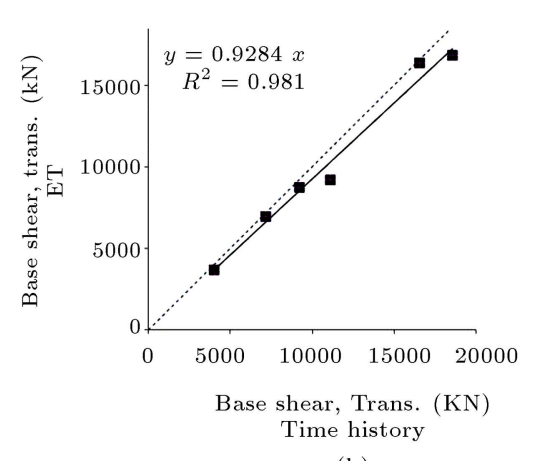

(b)

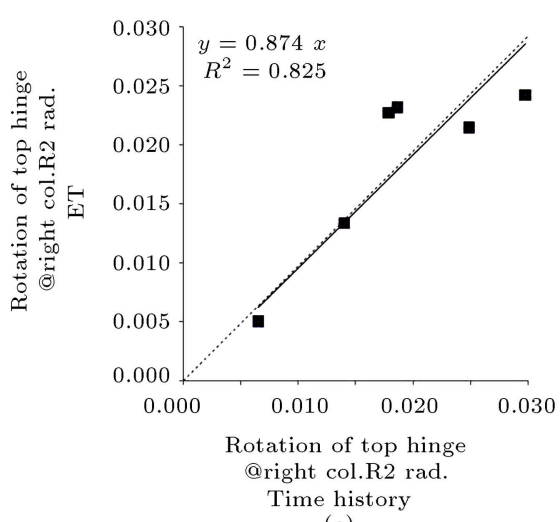

(e)

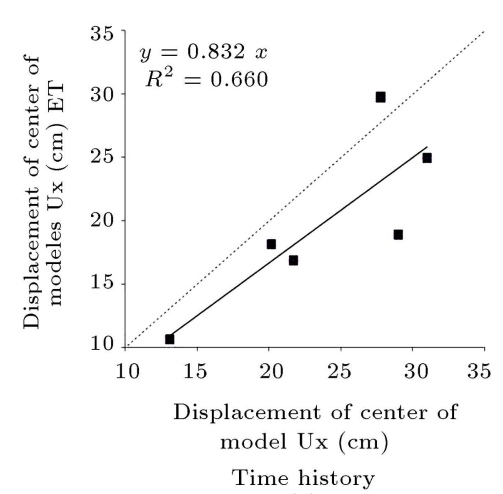

(c)

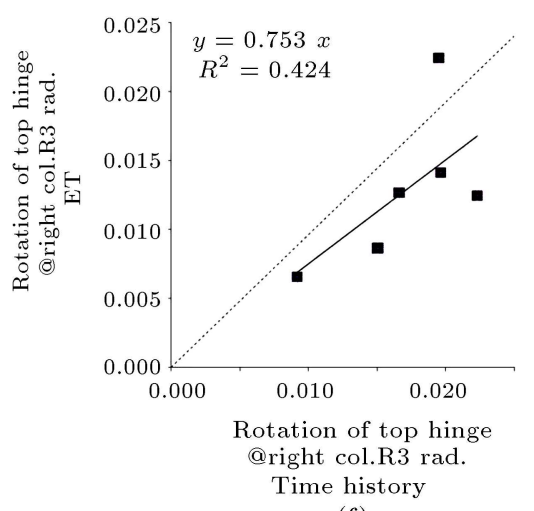

(f)

Figure 9. The correlation between the results of endurance time and time history methods in diagnosing: (a) \& (b) Longitudinal and transverse base shear, (c) \& (d) displacement of capbeam central node in longitudinal and transverse directions, and (e) \& (f) rotation of the top hinge of the right column in directions R2 and R3. 


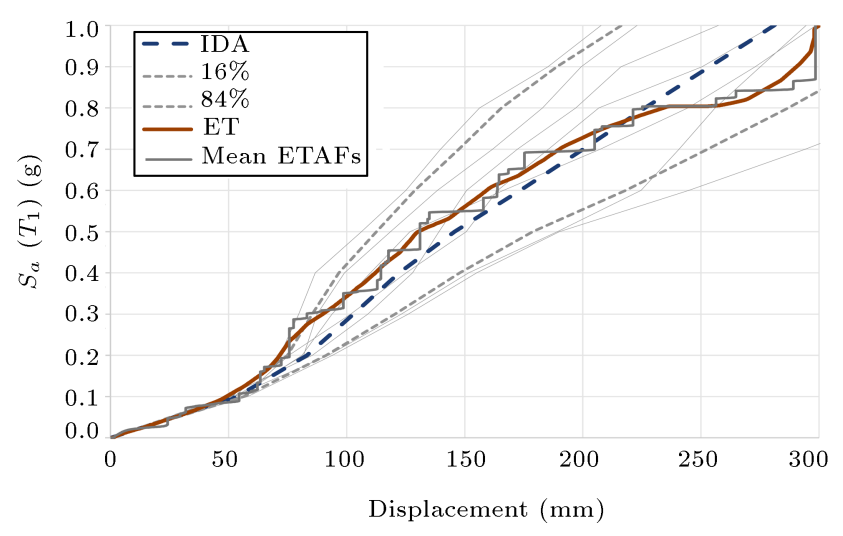

Figure 10. Comparison of Incremental Dynamic Analysis (IDA) and Endurance Time Analysis (ETA) curves for the longitudinal displacement of a column capbeam of LADWP model at different magnitudes of $S_{a}\left(T_{1}\right)$.

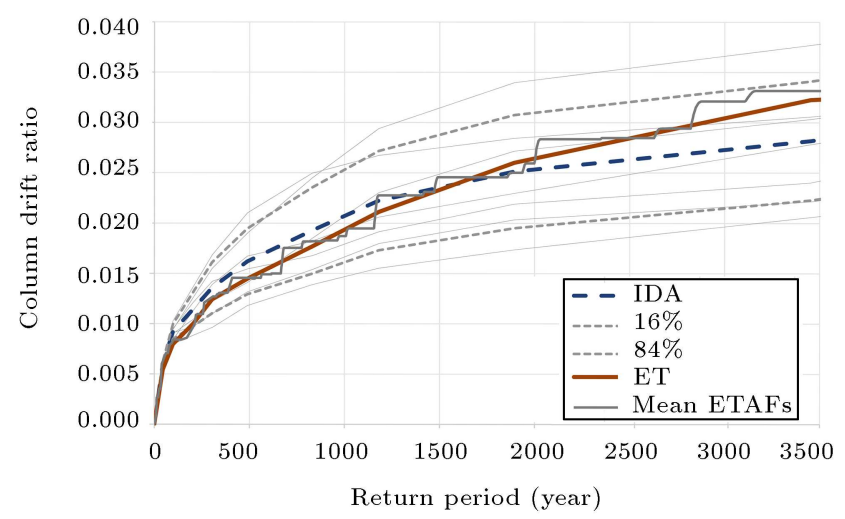

Figure 11. Comparison of Incremental Dynamic Analysis (IDA) and Endurance Time Analysis (ETA) curves for the drift ratio of a column of LADWP model for a wide range of seismic hazard return periods.

return period is linked to the fundamental period of the structure [23].

\subsection{ET method as a value-based analyzing tool}

The application of ET method can help draw the loss curve of a bridge structure and estimate the Life Cycle Cost (LCC) of the bridge. As a practical procedure, loss curve can be acquired by considering an ET response curve whose $y$-axis is the EDP (e.g., bridge column drift ratio) and $x$-axis is the ET analyzing time. Here, the annual rate of exceedance of drift ratios should be determined. By reversing the return period on the $x$-axis (originally mapped from ET analysis time), the mean annual rate of exceedance can be obtained and placed on the $y$-axis [26]. The drift ratio is replaced by damage cost with the application of the relationship shown in Table 5 [27]; in addition, by considering the initial cost of the bridge, the annual rate of the exceedance of damage cost can be obtained, as shown in Figure 12. This is the loss curve of the bridge drawn for the LADWP model. The area under the loss curve represents the mean annual total damage cost caused by all earthquakes in one year [26].

\subsubsection{Initial costs}

The initial cost is the cost of constructing a new structure or rehabilitating an existing structure. In this study, the initial cost of a bridge involves the costs of material including concrete and steel bars of superstructure and substructure, as well as the labor cost for the construction of the bridge. In the case of a national project like bridges, the land price is not a concern. There are some methods for estimating the initial cost of a bridge. It can be calculated by the individual items or estimated approximately for the unit of area.

\subsubsection{Life Cycle Cost (LCC)}

In this study, LCCs represent the costs resulting from all earthquakes with any magnitude that may occur during the 75-year lifetime of the bridge. As a simplified method that is capable of calculating the LCCs of bridge, damages are considered to be a function of column drift ratio and the corresponding repair costs in any limit state are assumed to be a ratio of initial cost; however, in a real accident, there are lots of other indirect costs such as user detour cost, injuries, user delay cost, emergency responses cost, etc. In this study,

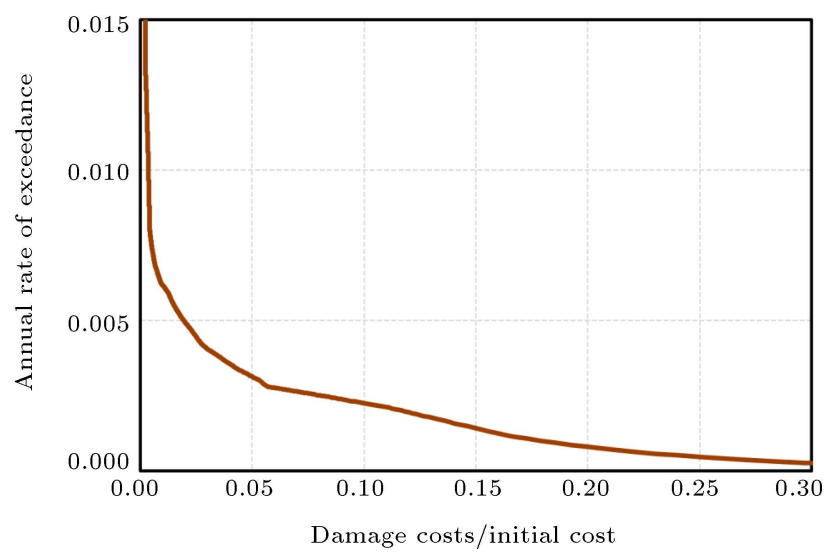

Figure 12. Loss curve of LADWP model.

Table 5. Column drift ratio and related damage repair costs for damage states after the case in [27].

\begin{tabular}{cccc}
\hline $\begin{array}{c}\text { Damage } \\
\text { state }\end{array}$ & Description & Drift (\%) & $\begin{array}{c}\text { Mean repair } \\
\text { cost ratio } \\
(\%)\end{array}$ \\
\hline DS1 & None & $<0.6$ & 0 \\
DS2 & Slight/minor & 0.6 & 3 \\
DS3 & Moderate & 2.2 & 8 \\
DS4 & Extensive & 3.6 & 25 \\
DS5 & Complete & 4.9 & 100 \\
\hline
\end{tabular}


since the main objective is to explore the advantages of ET method in this context, a simple cost model is used and a correlation to quantify damage losses in economic terms, as shown in Table 5 , is considered.

The total LCC is the sum of the initial costs and the present value of the annual damage costs summed up through the lifetime of the structure. To transform the damage costs to the present value and calculate the expected damage cost of the bridge in its 75 -year lifetime, a discount rate equal to $3 \%$ over a 75 -year life cycle of the bridge has been considered. Considering the relation between column drift ratio and damage repair costs as a ratio of initial cost, the LCC of the LADWP model after normalizing the initial cost is obtained at 1.185 times the initial cost.

\section{Conclusions}

Based on the results of this study, the following conclusions can be drawn:

1. The results of Endurance Time (ET) analysis for the six bridges with different dimensions and number of spans reveal that this method yields satisfactory results in a nonlinear range;

2. Although the scaling method of the accelerograms in this study produced strong agreement between the average spectrum and design spectrum, the use of constant Peak Ground Acceleration (PGA) for all accelerograms caused this method to present higher scaling factors;

3. The average and minimum correlation coefficients of results obtained from ET method and time history analysis using real earthquakes for investigated bridges are 0.92 and 0.75 , respectively. Considering this strong correlation between results, it can be concluded that ET method is able to predict the seismic response of bridges in a nonlinear range with reasonable accuracy;

4. Comparison of Endurance Time Analysis (ETA) and Icremental Dynamic Analysis (IDA) curves reveals good agreement concerning the prediction of the seismic responses of bridges over a wide range of earthquake magnitudes.

\section{Nomenclature}

AASHTO American Association of State Highway and Transportation Officials;

ASCE American Society of Civil Engineers

DS Damage State

EDP Engineering Demand Parameter

ET Endurance Time method

ETA Endurance Time Analysis
ETAF Endurance Time Acceleration Function

$F_{a} \quad$ Short-period site coefficient (at a timespan of $0.2 \mathrm{~s}$ )

FEMA Federal Emergency Management Agency

FHWA Federal Highway Administration

$F_{V} \quad$ Long-period site coefficient (at a timespan of $1.0 \mathrm{~s}$ )

IDA Incremental Dynamic Analysis

IM Intensity Measure

INBC Iranian National Building Code

LCC Life Cycle Cost

PEER Pacific Earthquake Engineering Research Center

PGA Peak Ground Acceleration

$S_{1} \quad$ Mapped maximum considered earthquake, $5 \%$ damped, spectral response acceleration parameter at a timespan of $1 \mathrm{~s}$

$S_{a} \quad$ Spectral acceleration response

$S_{D 1} \quad$ Design, $5 \%$ damped, spectral response acceleration parameter at a timespan of $1 \mathrm{~s}$

$S_{D S} \quad$ Design, $5 \%$ damped, spectral response acceleration parameter in short periods

$S_{S} \quad$ Mapped maximum considered earthquake, $5 \%$ damped, spectral response acceleration parameter in short periods

$t \quad$ Time duration of ETAF

$T \quad$ The fundamental period of the bridge

$T_{0} \quad 0.2 \mathrm{~S}_{D 1} / \mathrm{S}_{D S}$

$T_{L} \quad$ Long-period transition period

$T_{S} \quad \mathrm{~S}_{D 1} / \mathrm{S}_{D S}$.

\section{References}

1. Friedland, I.M., Buckle, I.G., and Lee, G.C. "Highway bridge seismic design: summary of FHWA/MCEER project on seismic vulnerability of new highway construction", Earthquake Engineering and Engineering Vibration, 1(1), pp. 10-19 (2002).

2. Saadeghvariri, M.A. and Foutch, D. "Dynamic behaviour of $\mathrm{R} / \mathrm{C}$ highway bridges under the combined effect of vertical and horizontal earthquake motions", Earthquake Engineering \& Structural Dynamics, 20(6), pp. 535-549 (1991).

3. Chen, Y. "Modeling and analysis methods of bridges and their effects on seismic responses: I Theory", Computers \& Structures, 59(1), pp. 81-98 (1996). 
4. Estekanchi, H., Riahi, H., and Vafai, A. "Application of endurance time method in seismic assessment of steel frames", Engineering Structures, 33(9) pp. 25352546 (2011).

5. Ghobarah, A. and Ali, H. "Seismic performance of highway bridges", Engineering Structures, 10(3), pp. 157-166 (1988).

6. Basim, M.C. and Estekanchi, H. "Application of endurance time method in performance-based optimum design of structures", Structural safety (2015).

7. Estekanchi, H., Valamanesh, V., and Vafai, A. "Application of endurance time method in linear seismic analysis", Engineering Structures, 29(10), pp. 25512562 (2007).

8. Hariri-Ardebili, M.A., Furgani, L., Meghella, M., and Saouma, V.E. "A new class of seismic damage and performance indices for arch dams via ETA method", Engineering Structures, 110(Supplement C), pp. 145160 (2016).

9. Hariri-Ardebili, M., Sattar, S., and Estekanchi, H. "Performance-based seismic assessment of steel frames using endurance time analysis", Engineering Structures, 69 pp. 216-234 (2014).

10. Estekanchi, H., Vafai, A., and Sadeghazar, M. "Endurance time method for seismic analysis and design of structures", Scientia Iranica, 11(4), pp. 361-370 (2004).

11. Riahi, H. and Estekanchi, H. "Seismic assessment of steel frames with the endurance time method", Journal of Constructional Steel Research, 66(6), pp. 780-792 (2010).

12. Mashayekhi, M. and Estekanchi, H. "Investigation of strong-motion duration consistency in endurance time excitation functions", Scientia Iranica, Transaction A, Civil Engineering, 20(4), p. 1085 (2013).

13. Valamanesh, V., Estekanchi, H., and Vafai, A. "Characteristics of second generation endurance time acceleration functions", Scientia Iranica, 17(1), pp. 53-61 (2010).

14. Estekanchi, H. "Endurance time method website", Available at: https://sites.google.com/site/etmethod (2018).

15. INBC, Iranian Code of Practice for Seismic Resistant Design of Buildings, Standard No. 2800 (2005).

16. ASCE, "Minimum design loads for buildings and other structures, ASCE 7-05", American Society of Civil Engineers (2006).

17. FHWA "Seismic retrofitting manual for highway structures: part 1-bridges", FHWA-HRT-06-032, Federal Highway Administration (2006).
18. Aviram, A., Mackie, K.R., and Stojadinovic, B., "Guidelines for nonlinear analysis of bridge structures in California", 2008/03, PEER, Berkeley California (2008).

19. FEMA "Quantification of Building Seismic Performance Factors", FEMA P695, Washington, DC (2009).

20. PEER "PEER Strong Motion Catalog", Available at: https://ngawest2.berkeley.edu/ (2017).

21. Vamvatsikos, D. and Cornell, C.A. "Incremental dynamic analysis", Earthquake Engineering \& Structural Dynamics, 31(3), pp. 491-514 (2002).

22. Vamvatsikos, D. and Cornell, C.A. "Applied incremental dynamic analysis", Earthquake Spectra, 20(2), pp. 523-553 (2004).

23. Mirzaee, A., Estekanchi, H., and Vafai, A. "Improved methodology for endurance time analysis: From time to seismic hazard return period", Scientia Iranica, 19(5), pp. 1180-1187 (2012).

24. Bazmooneh, A. and Estekanchi, H. "Determination of target time for endurance time method at different seismic hazard levels", Scientia Iranica, 25(1), pp. (33)-(49) (2018).

25. Hariri-Ardebili, M.A., Zarringhalam, Y., and Yahyai, M. "A comparative study of IDA and ETA methods on steel moment frames using different scalar intensity measures", Journal of Seismology and Earthquake Engineering, 15(1), pp. 69-79 (2013).

26. Basim, M.C. and Estekanchi, H.E. "Application of endurance time method in value based seismic design of structures", In Second European Conference on Earthquake Engineering and Seismology, Istanbul (2014).

27. Solberg, K., Mander, J., and Dhakal, R. "A rapid financial seismic risk assessment methodology with application to bridge piers", in 19th Biennial Conference on the Mechanics of Structures and Materials, Christchurch, New Zealand (2006).

\section{Biographies}

Esmaeil Ghaffari was born in 1986. He received BS and MS degrees in Civil and Structural Engineering from Sharif University of Technology, Tehran, Iran in 2008 and 2010, respectively, and defended his master's thesis entitled "Application of Endurance Time Method in Seismic Analysis of Bridges" in December 2010. He is currently a PhD candidate in Structural and Earthquake Engineering at the same university. His research interests include dynamic analysis of structures using the endurance time method, performancebased design, and seismic behavior of bridges.

Homayoon E. Estekanchi is a Professor of Civil Engineering at Sharif University of Technology. He received his $\mathrm{PhD}$ in Civil Engineering from SUT in 1997 and has been a faculty member at SUT since then. 
$\mathrm{He}$ is a member of Iranian Construction Engineers Organization, ASCE, Iranian Inventors Association, and several other professional associations. His research interests include a broad area of topics in structural and earthquake engineering with a particular focus on the design of tall buildings and industrial structures.

Abolhassan Vafai, $\mathrm{PhD}$, is a Professor of Civil
Engineering at Sharif University of Technology. He has authored/co-authored numerous papers in different fields of en gineering: applied mechanics, biomechanics, and structural engineering (steel, concrete, timber, and offshore structures). He has also been active in the area of higher education and has delivered lectures and published papers on challenges of higher education, the future of science and technology, and human resources development. 